\title{
ARTICLE
}

\section{Effects of intranasal insulin as an enhancer of fear extinction: a randomized, double-blind, placebo-controlled experimental} study

\author{
Diana S. Ferreira de Sá (iD ${ }^{1}$, Sonja Römer ${ }^{1}$, Alexandra H. Brückner ${ }^{1}$, Tobias Issler ${ }^{1}$, Alexander Hauck ${ }^{1}$ and Tanja Michael ${ }^{1}$
}

\begin{abstract}
Fear-extinction based psychotherapy (exposure) is the most effective method for treating anxiety disorders. Notwithstanding, since some patients show impairments in the unlearning of fear and insufficient fear remission, there is a growing interest in using cognitive enhancers as adjuvants to exposure. As insulin plays a critical role in stress processes and acts as a memory enhancer, this study aimed to assess the capacity of intranasal insulin to augment fear extinction. A double-blind, placebo-controlled differential fear-conditioning paradigm was conducted in 123 healthy participants (63 females). Pictures of faces with neutral expressions were used as conditioned stimuli and electric shocks as unconditioned stimuli. The paradigm consisted of four phases presented on three consecutive days: acquisition (day 1), extinction (day 2), reinstatement and re-extinction (day 3 ). A single intranasal dose of insulin (160 IU) or placebo was applied on day 2, $45 \mathrm{~min}$ before fear extinction. Skin conductance response (SCR), fear-potentiated startle (FPS) and expectancy ratings were assessed. During extinction, the insulin group (independent of sex) showed a significantly stronger decrease in differential FPS in comparison with the placebo group. Furthermore, a sex-specific effect was found for SCR, with women in the insulin group showing a greater decrease of differential SCR both at early extinction and at late re-extinction. Our results provide first evidence that intranasal insulin facilitates fear extinction processes and is therefore a promising adjuvant for extinction-based therapies in anxiety and related disorders. Sex-specific effects should be taken into consideration in future studies.
\end{abstract}

Neuropsychopharmacology (2020) 45:753-760; https://doi.org/10.1038/s41386-019-0593-3

\section{INTRODUCTION}

Anxiety disorders (ADs) are the most frequent group of mental disorders [1] and contribute significantly to the large burden of mental illness worldwide [2]. Cognitive-behavioral therapy (CBT) is the gold standard for treating ADs and other fear-related disorders like obsessive-compulsive disorder (OCD) and posttraumatic stress disorder (PTSD) [3]. While CBT is an effective treatment with few side-effects, not all patients profit from it [4]. A recent metaanalysis of placebo-controlled CBT trials [5] has revealed large effect sizes only for generalized anxiety disorder (GAD), OCD, and acute stress disorder (ASD). Effect sizes for PTSD, social anxiety disorder (SAD), and panic disorder (PD) were small to moderate.

Exposure therapy is widely regarded as the vital therapeutic component of CBT for ADs [6]. This assumption is underlined by the above-mentioned meta-analysis [5] showing that treatments which chiefly used exposure techniques have larger effect sizes than those utilizing both cognitive and behavioral techniques, and cognitive techniques alone. Augmentation of exposure therapy is thus an ideal starting point in the quest of improving treatments for anxiety and related disorders. It involves exposing patients under controlled conditions to situations that elicit pathological fear, thereby inducing fear extinction, a process well characterized and understood based on human and animal fear-conditioning research [7]. Impaired extinction learning has been observed in individuals with anxiety and related disorders $[4,8,9]$ and the success of exposure therapy is predicted by extinction learning [10]. Decades of intense animal and human research have uncovered both associative and neurobiological mechanisms underlying extinction. This has also opened the door to translational research, which allowed the identification of agents like D-cycloserine [11] or cortisol [12-14] that may be utilized to enhance therapeutic success.

We propose that the peptide hormone insulin should be examined for its potential to augment exposure success. Insulin is widely known for its regulatory role in metabolism, but also has enhancing effects on memory and learning [15]. Insulin is produced by the pancreatic B-cells and its main function is to control glucose metabolism in the periphery of the body. However, insulin receptors (IRs) are also widely distributed in the brain [16], with particularly high densities in the olfactory bulb, cerebral cortex, hypothalamus, and hippocampus [17]. While the peripheral IRs primarily act on glucose regulation, central IRs exert functions related to brain development, plasticity, and cognitive processes, in particular modulation of memory and attention processes $[15,18-20]$. The experimental manipulation of central effects of insulin by intravenous application is limited by severe peripheral side-effects, i.e. hypoglycemia [21]. However, intranasal application can prevent such peripheral side-effects while providing a direct route to the central nervous system (CNS) [22]. In patients with Alzheimer's disease, intranasal insulin can improve

${ }^{1}$ Division of Clinical Psychology and Psychotherapy, Department of Psychology, Saarland University, Saarbrücken, Germany

Correspondence: Diana S. Ferreira de Sá (diana.ferreira@uni-saarland.de)

Received: 5 August 2019 Revised: 26 November 2019 Accepted: 16 December 2019

Published online: 2 January 2020 
754

memory performance and prevent deterioration [23]. In healthy subjects, it increases performance in hippocampus-dependent tasks [20, 24-26]. Long-term administration of intranasal insulin also improved executive function in bipolar disorder patients [27]. While some studies using long-term insulin administration showed similar cognitive enhancement in both sexes [20], sexdependent effects of insulin have been reported, with men being more sensitive to its anorexigenic and women to its acute cognitive enhancing properties [24, 28]. When used as an unconditioned stimulus (US), intranasal insulin was shown to produce a conditioned serum insulin response [29], indicating promising applications in learning processes.

Fear extinction is not a passive process, but the result of a newly formed inhibitory memory [30]. Attending the large evidence on the effects of intranasal insulin as a cognitive enhancer, we expect this hormone to also enhance fear extinction memory. To date, this has not been investigated. The aim of the present study was to investigate the effects of exogenous intranasal insulin on fear extinction processes in healthy subjects. We carried out a doubleblind, placebo-controlled study to test the effect of an acute dose of intranasal insulin (160 IU) administered before fear extinction learning using a differential fear-conditioning paradigm. Furthermore, reinstatement of fear and re-extinction were tested $24 \mathrm{~h}$ later to examine the stability of possible insulin effects after return of fear (ROF). We hypothesized that intranasal insulin prior to extinction would facilitate extinction and diminish reinstatement while enhancing re-extinction. As a subsidiary aim, we investigated interactions of sex with insulin effects on fear extinction processes given the reported sex-specific effects of insulin on memory.

\section{METHODS AND MATERIALS}

\section{Participants}

Data were acquired from 131 healthy students at Saarland University. Exclusion criteria were: tinnitus; body-mass index (BMI) outside the normal range (men: $20-25 \mathrm{~kg} / \mathrm{m}^{2}$; women: $19-24 \mathrm{~kg} / \mathrm{m}^{2}$; German Nutrition Society); drug or medication intake within the last 6 months, except occasional use of painkillers and moderate caffeine/nicotine consumption; acute medical or psychiatric symptoms/complaints; excessive physical exercise. To control for hormonal effects of the menstrual cycle, only women taking oral contraceptives were included, with exception of contraceptives containing drosperinone due to its mineralocorticoid receptor antagonist effects [31]. Study procedures followed the Declaration of Helsinki, were approved by the local medical ethical committee (Ärztekammer des Saarlandes), and were registered in the German Clinical Trial Register (DRKS00010551). At application to partake in the experiment, a participant information sheet was given with details on the procedures applied (e.g. electroshock administration, insulin or placebo administration), as well as the general research question (effects of intranasal insulin in memory processes). Participants gave written informed consent and received moderate monetary incentive on completion of the study.

Two participants did not come to the first day of experiment, while two others discontinued participation. Due to malfunctions on day 1, four participants were excluded from all analyses (Supplementary Fig. S1). The final sample consisted of 123 participants (63 females) with a median age of 23 years (range 18-35).

\section{Group assignment and pharmacological manipulation}

In a double-blind design, participants were randomly assigned within sex to intranasal insulin or intranasal placebo, resulting in the following division: insulin group ( $n=62,31$ females), placebo group ( $n=61,32$ females). Participants received 160 units of intranasal insulin (Insulin Human Actrapid Penfill ${ }^{\oplus}$ 100I.E./ml; Novo
Nordisk, Mainz, Germany), a quantity which has shown effects on cognitive function [32], or placebo (dilution buffer for insulin). Eight $0.1-\mathrm{ml}$ puffs of substance were applied into each nostril via high-precision medical nose pump (Aero Pump, Hochheim, Germany). Substance was administered on day 2, 45 min before fear extinction to ensure central effects during the critical time of extinction learning $[22,33]$. Upon arrival, before starting the extinction, and before departure, blood sugar levels were controlled via a blood glucose meter (Accu-Chek Aviva, Roche Diagnostics Deutschland, Mannheim, Germany). In the period between substance administration and beginning of the extinction phase, participants were allowed to read pre-selected magazines after being asked to leave their belongings, including mobile devices, in a separate room.

\section{Stimuli and apparatus}

Conditioned stimuli (CS) consisted of four validated face pictures (two female) from the Radboud Faces Database [34], showing neutral expressions (female: nr. 1 and 19, male: nr. 7 and 25). Pairs were chosen based on matching valence and arousal ratings obtained in a pre-study (M Arousal: nr. $1=29.96$, nr. $19=30.41$; nr. $7=31.93$, nr. $25=28.43$; M Valence: nr. $1=47.96$, nr. $19=$ $48.93 ; \mathrm{nr} .7=45.17, \mathrm{nr} .25=48.30$ ). Given that social anxiety is the most common $\mathrm{AD}$ [35] and threatening social experiences can provoke lasting fear [36], we chose socially relevant CS. These stimuli have a higher comparability with common aversive experiences than abstract stimuli, and consequently lend a higher ecological validity to the present paradigm. In a pseudorandomized fashion (balanced by sex and group), each participant watched either female or male faces. Each picture was shown for $8 \mathrm{~s}$ followed by a black screen with randomized intertrial-interval (ITI) of $10-15 \mathrm{~s}$ duration. An acoustic startle stimulus was presented on all CS-trials $7 \mathrm{~s}$ after picture onset, and during the ITI (noise alone, NA), $5 \mathrm{~s}$ after picture offset. NA trials were presented as often as the single CS. The acoustic startle stimulus was a white noise (105 dB, $50 \mathrm{~ms}$, instantaneous rise-time) presented binaurally via 24-Bit sound card (Creative Sound Blaster $Z$, Creative Technology Ltd., Singapore) and audiometric headphones (Holmco PD-81, Holmberg GmbH \& Co. KG, Germany). As US, a moderate $200 \mathrm{~ms}$ electroshock was applied to the lower left arm of the subject immediately at the offset of the $\mathrm{CS}^{+}$. Intensity was adjusted individually by each subject on day 1 (possible range: $1 \mathrm{~mA}$ to $10 \mathrm{~mA}$ ) and kept constant in the following days. The presentation order was pseudo-randomized with the restriction that (a) no more than two consecutive presentations of the same stimulus-type would occur; (b) each half of the experiment would have a balanced number of each trial-type.

\section{Procedure}

The differential fear-conditioning procedure took place on three consecutive days: acquisition of fear was established on day 1; pharmacological manipulation and extinction of fear on day 2; reinstatement and re-extinction on day 3 (Fig. 1). Participants were asked to abstain from alcoholic/caffeinated beverages consumption and sport activities prior to the experiment. To ensure a similar glycemic state every day, they were instructed to have their last meal prior to 22.00 of the previous day. For a better applicability of the fasting period and to control for the natural circadian rhythms of metabolic hormones [37], testing took place between 8.00 and 12.00. A cover story was used to increase compliance: participants were informed that a saliva sample would be collected to control if the fasting period had been respected. A routine recall from waking until arrival was completed as an additional compliance control [38, 39]. Participants were prepared for recording of electromyographic (EMG) eye blink of the left orbicularis oculi muscle, skin conductance response (SCR), electrocardiogram (ECG), and for electroshock following published guidelines [40, 41]. Every experimental 
Day 1: Acquisition

*Example of the possible paradigm distribution following $75 \%$ reinforcement

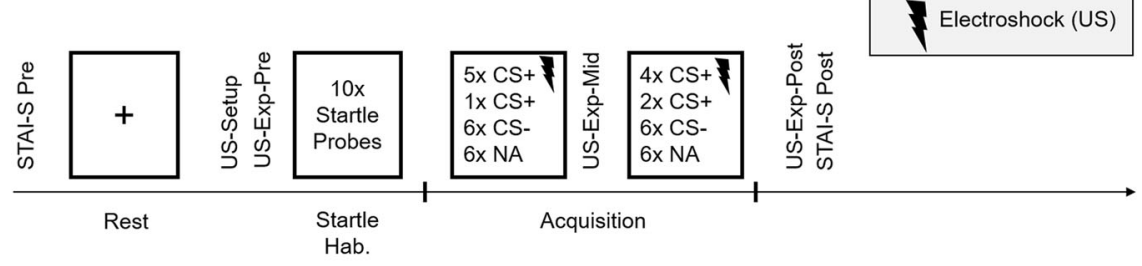

Day 2: Extinction

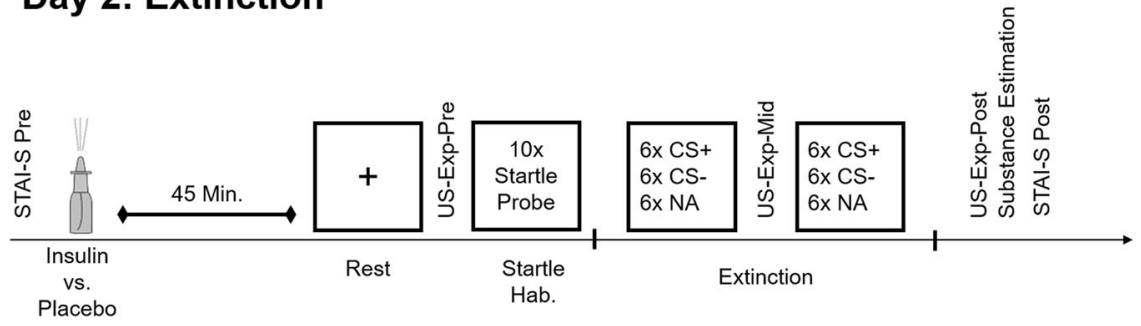

Day 3: Test of Reinstatement \& Re-Acquisition

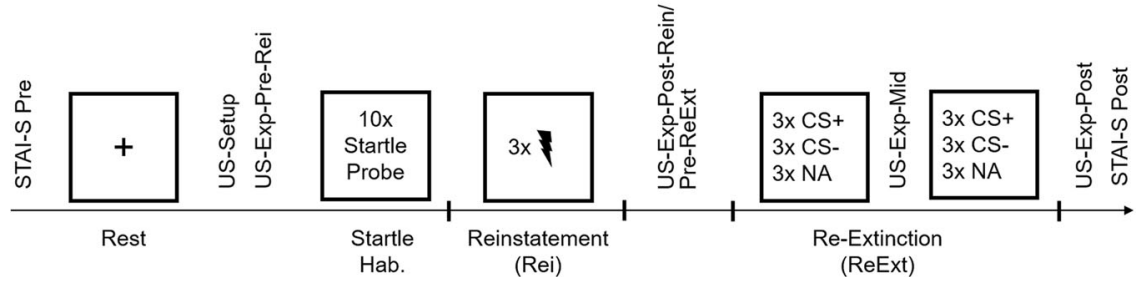

Fig. 1 Diagram of the experimental design.

session started with a resting phase of 3 min (black screen with fixation cross) and a startle habituation (10 startle probes).

Day 1: acquisition. After the resting phase, participants were instructed to adjust the intensity of the US by gradually increasing the intensity of the electroshock up to being "highly unpleasant and demanding some effort to tolerate, while not being painful". Instructions for acquisition indicated that one of two pictures would be sometimes followed by an electroshock. Acquisition consisted of $12 \mathrm{NA}, 12 \mathrm{CS}^{-}$, and $12 \mathrm{CS}^{+}$, with $75 \%$ reinforcement. Partial reinforcement allows for a slower extinction learning [42], where effects of a cognitive enhancer can be better studied.

Day 2: extinction. Forty-five minutes after pharmacological administration, participants started the experiment. Participants were instructed that an electroshock could or could not appear sometimes and that the same pictures from the previous day would be presented. Extinction consisted of 12 unpaired NA/CS $/$ $\mathrm{CS}^{+}$trials.

Day 3: reinstatement and re-extinction. Participants were instructed that an electroshock could or could not be administered during the experiment and that the faces from the previous days would be presented. During reinstatement, three unpredicted US were administered with randomized ISI of 15-20 s. Reextinction followed consisting of six unpaired NA/CS $/ \mathrm{CS}^{+}$trials.

\section{Physiological measures}

Physiological data were recorded with ActiveTwo-Software (BioSemi, Amsterdam, Netherlands) at a sampling rate of 2048 $\mathrm{Hz}$. Data were further analyzed with Autonomic Nervous System Laboratory (ANSLAB) version 2.6 [43] and manually inspected.

Eyeblink startle responses were measured from EMG activity of the orbicularis oculi muscle using $\mathrm{Ag}-\mathrm{AgCl}$ active electrodes.
Startle response amplitude was computed as the difference between peak-highest value of the startle response within 20-150 ms after acoustic stimulus onset-and baseline-mean EMG in the 50-ms window before acoustic stimulus onset. Artifacts were set to missing data, while trials with no visible startle response were scored as zero. Startle magnitudes were calculated including zero responses.

SCR was measured through two Nihon-Kohden electrodes filled with isotonic electrode gel attached to the proximal part of the palm of the subject's non-dominant hand. SCR to the CS was calculated by subtracting the average baseline ( $2 \mathrm{~s}$ before stimulus onset) from the maximum score after CS onset (0-7 s) [44-47].

For each participant, outliers $(|Z|>3)$ and missing data from startle (Placebo group: $1.4 \%$, Insulin group: $1.1 \%$ of all data) and SCR (placebo group: 1.6\%, insulin group: $1.5 \%$ of all data) were replaced by linear trend at point separately for experimental phase (acquisition, extinction, reinstatement, re-extinction) and CS-type $[14,48]$. To minimize between-subject and day variability, both startle and SCR were $T$-scored.

Self-report and subjective measures

Before the first day of experiment, participants filled out the Beck Depression Inventory (BDI-II) [49] and the trait-form of the State-Trait Anxiety Inventory (STAI-T, [50]). The state-form of the STAI (STAI-S, [50]) was acquired on each day at the beginning and end of the session. US-expectancy ratings were collected before the beginning (pre), in the middle (mid), and at the end (post) of each conditioning phase with a continuous visual analog scale, ranging from very low (0) to very high expectancy (100), prompting participants to retrospectively rate how much they expected the CS to be followed by an electroshock. At the end of day 2, participants indicated which substance they believed was administered to them ("insulin", "placebo", "I do not know"). 
Statistical analysis

Statistical analyses were conducted with IBM SPSS (version 22), the level of significance set to $(a)=0.05$. Due to experimental malfunctions on day 3 , four participants had to be excluded from analyses regarding this day. Six participants were excluded from startle analysis due to complete absence of startle eye-blinks (nonresponders) and three others due to missing values in $>5 \%$ of their total startle data. Two participants were excluded from SCR analysis on day 2 and another one on day 3, due to technical problems.

To assess conditioning to the $\mathrm{CS}^{+}$in the physiological data, a mixed-design-ANOVA with Group (insulin vs. placebo) as between-groups factor, and CS-type $\left(\mathrm{CS}^{+}\right.$vs. $\left.\mathrm{CS}^{-}\right)$and Time (Blocks 1-6, each with two trials of each CS-type) as withinparticipants factors was conducted.

Since we hypothesized that insulin effects might be modulated by sex, all analysis from day 2 on (after pharmacological manipulation) included Sex as a between factor. To assess discrimination between the $\mathrm{CS}^{+}$and $\mathrm{CS}^{-}$, difference-scores $\left(\mathrm{CS}^{+}-\mathrm{CS}^{-}\right.$; Diff ${ }^{X}$, with $X$ specifying the dependent variable) were used for analysis of extinction, reinstatement, and re-extinction [51, 52]. Following data correction recommendations [53] and studies with similar designs [14,54-56], blocks were averaged into early and late phases, each containing one half of the respective phase, to better represent learning effects. Extinction and reextinction were tested with a mixed-design-ANOVA with Sex and Group as between factors and Time (early vs. late) as withinvariable. Reinstatement was tested in a similar fashion with Time consisting of late extinction vs. early re-extinction.

For the US-expectancy ratings, similar analyses were conducted, with the within-factor Time (pre vs. mid vs. post) for acquisition, extinction, and re-extinction. For reinstatement analysis, postextinction vs. pre- and post-reinstatement were used ${ }^{1}$.

Additionally, to check for contextual anxiety throughout the experiment [57-59], raw NA trials were analyzed in a mixeddesign-ANOVA with Sex and Group as between factors, and Phase (acquisition, extinction, and re-extinction) and Time (early vs. late) as within-variables.

The Greenhouse-Geisser correction was applied whenever sphericity adjustment was required (adjusted $p$-values are reported with uncorrected degrees-of-freedom and epsilonvalues). Where not specified, means and standard error are reported. Follow-up analysis of three-way interactions were done with Bonferroni-adjusted pairwise comparisons for each Time point within each Sex group, comparing placebo and insulin.

Raw SCR $\left(\mathrm{CS}^{+}, \mathrm{CS}^{-}\right)$and fear-potentiated startle (FPS) $\left(\mathrm{CS}^{+}, \mathrm{CS}^{-}\right.$, NA) through all trials and sessions are depicted separately by group (acquisition) or group and sex (extinction, reinstatement, reextinction) in Supplementary Figs. S2-S11.

\section{RESULTS}

\section{Demographic variables}

There were no significant differences between groups regarding age, BMI, BDI, and STAI-T (Table 1).

\section{Glucose check}

No differences between groups was found regarding glucose levels throughout extinction (all Ps $>0.05$ ) (Supplementary Fig. S12). Glucose slightly decreased from the beginning to the end of the experiment (Time: $F_{2,232}=7.73, P=0.001, \eta p^{2}=0.64$ ),

\footnotetext{
${ }^{1}$ Additional models were calculated to control for the effects of acquisition levels on extinction, reinstatement and re-extinction: the difference-score from the last Block of acquisition (Block 6) was added as a covariate to the analysis of physiological data, and the last trial of acquisition was added as a covariate to the analysis of expectancy ratings. Results remained largely unaltered (see Table S1).
}

Table 1. Demographic characterization of the insulin and placebo group.

\begin{tabular}{llll}
\hline & Insulin group, $N=62$ & Placebo group, $N=61$ & $P$-values \\
\hline Age & $23.5(3.02)$ & $23.75(3.78)$ & 0.68 \\
Sex & 31 females & 32 females & 0.79 \\
BMI & $22.66(2.52)$ & $22.71(2.09)$ & 0.89 \\
BDI & $4.82(4.3)$ & $3.93(4.84)$ & 0.28 \\
STAI-T & $35(6.96)$ & $35.48(7.56)$ & 0.72 \\
\hline
\end{tabular}

Questionnaires were completed before the first experimental session Mean and standard deviation are presented for continuous variables, absolute numbers for categorical variables

$B M I$ body mass index, BDI Becks Depression Inventory, STAl-T State-Trait Anxiety Inventory

${ }^{a}$ Continuous variables were tested with Independent Samples $T$-test, categorical variables with $x^{2}$

with all subjects remaining in the euglycemic state at all time points ( $>70 \mathrm{mg} / \mathrm{dL}$ ).

\section{Subjective ratings and US intensity}

Groups did not differ in their estimation of substance administered $\left(X^{2}(2, N=123)=0.41, P=0.82\right.$; Supplementary Table S2), nor in the selected US level (Placebo: $4.03 \pm 0.26$, Insulin: $4.04 \pm$ $\left.0.27 ; t_{121}=0.22, P=0.83, d=0.04\right)$. STAI-S on the 3 days did not show differences between groups $(P s>0.05)$, but all participants reported higher state anxiety at the end of the experiment (Time effect on each day: Ps $<0.001)$.

Contextual anxiety throughout the experiment: NA startle Insulin had no influence per se on background anxiety throughout the different phases of the experiment. In absence of any grouprelated effects, it was found that women showed in general higher context anxiety (Sex: $F_{1,108}=6.22, P=0.014, n p^{2}=0.05$ ) and that for all participants contextual anxiety was lower at the end of the experiment (Time: $F_{1,108}=56.26, P<0.001, n p^{2}=0.34$ ).

\section{Acquisition}

Skin conductance response. As expected, the $\mathrm{CS}^{+}(52.18 \pm 0.23)$ elicited a higher SCR than the $\mathrm{CS}^{-}(47.82 \pm 0.23)$ during acquisition (Time: $F_{5,605}=39.44, P<0.001, \varepsilon=0.70, n p^{2}=0.25$; CS-type: $F_{1.121}=$ 92.88, $P<0.001, \eta p^{2}=0.43$; CS-type $\times$ Time: $F_{5,605}=3.58, P=0.006$, $\varepsilon=0.85, \eta p^{2}=0.03$; no significant interactions with Group).

Fear-potentiated startle. As expected, the $\mathrm{CS}^{+}(52.93 \pm 0.29)$ elicited a higher FPS than the $\mathrm{CS}^{-}(47.89 \pm 0.26)$ during acquisition (Time: $F_{5,560}=56.38, \quad P<0.001, \quad \varepsilon=0.91, \eta p^{2}=0.34$; CS-type: $F_{1,112}=154.34, P<0.001, \eta p^{2}=0.58$; CS-type $\times$ Time interaction: $F_{5,560}=3.24, P=0.009, \varepsilon=0.91, n p^{2}=0.03$; no significant interactions with Group).

US-expectancy. Participants correctly identified the $\mathrm{CS}^{+}$as predicting the shock $\left(\mathrm{CS}^{+}: 69.77 \pm 20.79 ; \mathrm{CS}^{-}: 25.57 \pm 23.81\right.$; Time: $F_{2,242}=$ 8.49, $P=0.002, \varepsilon=0.68, \eta p^{2}=0.07$; CS-type: $F_{1,121}=534.47, P<$ 0.001, $\eta p^{2}=0.82$; CS-type $\times$ Time interaction: $F_{2,242}=241.22, P<$ $\left.0.001, \varepsilon=0.68, \eta p^{2}=0.95\right)$. $\mathrm{CS}^{+}$was rated with a higher expectancy than the $\mathrm{CS}^{-}$in the mid and post $\left(P_{\mathrm{S}}<0.001\right)$, but not in the preratings. No significant interactions with Group were found.

\section{Extinction}

Skin conductance response. A main effect of Time $\left(F_{1,117}=16.96\right.$, $\left.P<0.001, n p^{2}=0.13\right)$, and an interaction of Time $\times$ Group $\times$ Sex was found for the $\operatorname{Diff}^{\mathrm{SCR}}\left(F_{1,117}=7.93, P=0.006, \eta p^{2}=0.07\right)$. Post-hoc tests showed that in the early extinction phase, Diff ${ }^{S C R}$ was lower for women in the insulin group $(-0.01 \pm 5.30)$ than for 
Extinction SCR

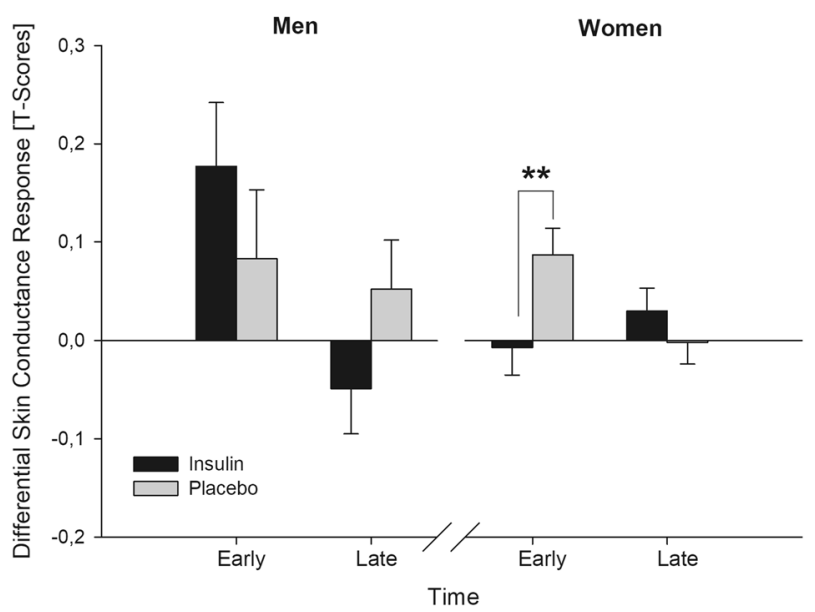

Fig. 2 Differential skin conductance response during early and late extinction in the insulin and placebo group by sex. Significant pairwise comparisons for each time point within each sex, comparing placebo and insulin, are indicated in the graphic. Error bars indicate one standard error; ${ }^{* *} P<0.01$.

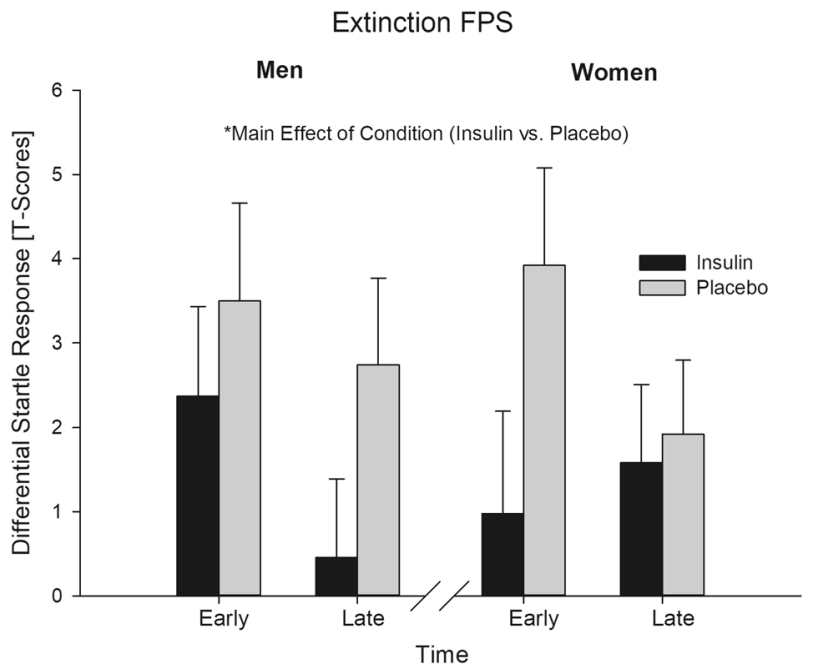

Fig. 3 Differential fear-potentiated startle during extinction in the insulin and placebo group. Error bars indicate one standard error; ${ }^{*} P<0.05$.

women in the control group $\left(3.78 \pm 6.13 ; F_{1,117}=7.52, P=0.007\right.$, $\eta p^{2}=0.06$; Fig. 2). No differences between Group were present in late extinction.

Fear-potentiated startle. The insulin group showed throughout the extinction phase a lower Diff ${ }^{\text {Startle }}(1.35 \pm 5.53)$ than the placebo group (3.02 \pm 5.57 ) (Group: $F_{1,110}=4.18, P=0.04, \eta p^{2}=$ 0.04; Fig. 3).

US expectancy. A decay in differential expectancy from pre, to mid and post-ratings ( $P s<0.001)$ was found (Time: $F_{2,238}=66.17$, $\left.P<0.001 ; \varepsilon=0.81, \eta p^{2}=0.36\right)$, indicating attenuation of the fear association (Fig. 4). No main effects or interactions with Group were found.

\section{Reinstatement}

Skin conductance response. No effects were found for the Diff ${ }^{\mathrm{SCR}}$ in the reinstatement of fear (all PS >0.05), indicating that there was no reinstatement of SCR.

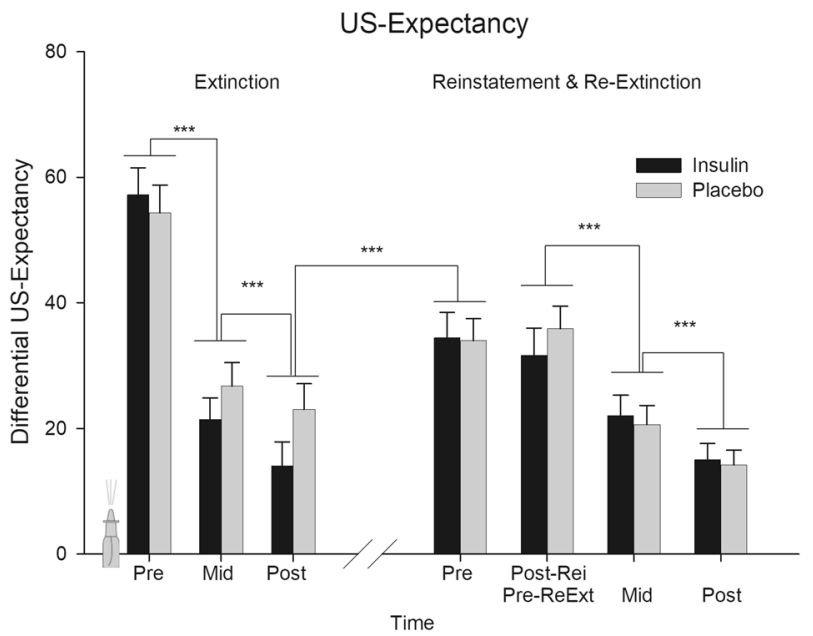

Fig. 4 Differential US expectancy during extinction, reinstatement and re-extinction in the insulin and placebo group. Main effects of time are depicted collapsed across the two groups. Error bars indicate one standard error; ${ }^{* * *} P<0.001$.

Fear-potentiated startle. Similarly to the SCR, no effects were found for the FPS (all Ps $>0.05$ ).

US expectancy. Diff ${ }^{\text {US-expectancy }}$ had a significant Time effect $\left(F_{2,236}=15.59, P<0.001, \varepsilon=0.68, \eta p^{2}=0.12\right)$ during reinstatement. An increase in differential expectancy from post-extinction to pre-reinstatement $(P<0.001)$ was present, suggesting a spontaneous recovery of fear. The reinstatement stimuli had no effect on expectancy ratings, however, with no significant change in US-expectancy ratings from pre- to post-reinstatement (Fig. 4).

\section{Re-extinction}

Skin conductance response. In the re-extinction, women $(-1.13 \pm$ 7.08) showed lower Diff ${ }^{\mathrm{SCR}}$ than men (1.05 \pm 8.05; Sex: $F_{1,112}=4.1$, $\left.P<0.05, \eta p^{2}=0.04\right)$. Furthermore, an interaction of Time $x$ Group $\times$ Sex was found $\left(F_{1,112}=5.74, P=0.02, n p^{2}=0.05\right)$. Posthoc tests showed that in late re-extinction Diff ${ }^{C R}$ was lower for women in the insulin group $(-3.42 \pm 5.24)$ than for women in the control group $\left(0.73 \pm 6.20 ; \quad F_{1,112}=5.14, \quad P=0.03, \eta p^{2}=0.04\right.$; Fig. 5).

Fear-potentiated startle. No effects were found for the FPS during re-extinction (all $P \mathrm{~s}>0.05$ ).

US expectancy. As expected, a decay in differential expectancy is seen from pre to mid and post-re-extinction (pre: $33.74 \pm 30.64$, mid: $21.35 \pm 24.08$, post: $14.61 \pm 18.97$; Time: $F_{2,230}=42.35, P<$ $0.001 ; \varepsilon=0.71, n p^{2}=0.27$; Fig. 4).

\section{DISCUSSION}

The present study is the first investigating the hypothesis that intranasal insulin enhances fear extinction and providing first evidence for its confirmation. On day 1, acquisition of fear was established successfully without differences between the insulin and placebo group. Critically, during fear extinction on day 2, the insulin group showed a smaller differential startle response than the placebo group. Additionally, women in the insulin group showed an enhanced reduction of the fear-related SCR during early fear extinction on day 2 as well as in late re-extinction on day 3.

Since SCR is closely associated with declarative memory while startle represents a more primary fear reaction [48], these results might indicate that insulin exerts different effects at different 


\section{Re-Extinction SCR}

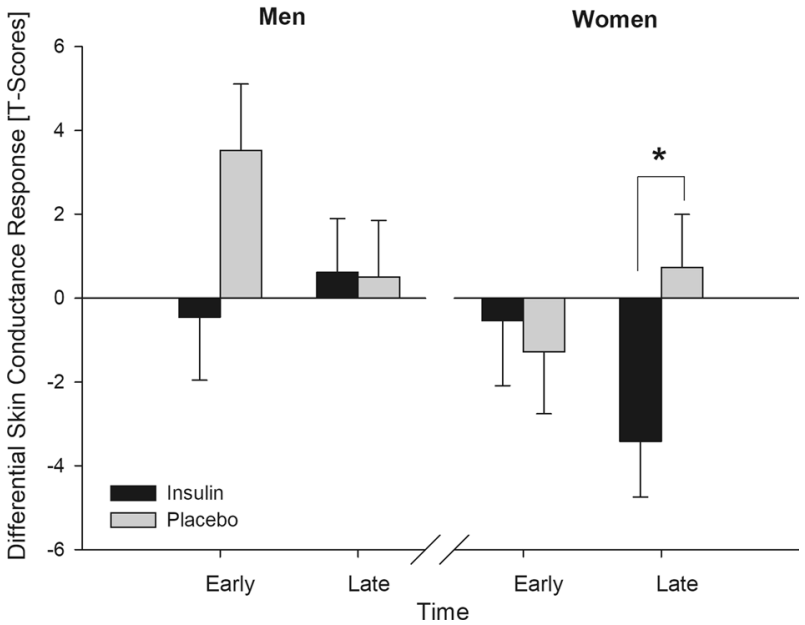

Fig. 5 Differential skin conductance response during early and late re-extinction in the insulin and placebo group divided by sex. Significant pairwise comparisons for each time point within each sex, comparing placebo and insulin, are indicated in the graphic. Error bars indicate one standard error; ${ }^{*} P<0.05$.

levels of fear extinction learning. Established cognitive effects of insulin are mainly found on short-term declarative memory [32]. It is therefore not surprising that we found an effect of insulin already at the beginning of fear extinction for the SCR. Although men and women seem to benefit from the cognitive effects of insulin, there is some evidence that women might be more sensitive to the beneficial effects of central insulin on hippocampus-dependent memory functions [24]. In line with this, in the present study, although both men and women benefited from the insulin effects in extinction of FPS, only women showed increased extinction and better extinction recall of the SCR. This might indicate that indeed women are more sensitive to the cognitive effects of insulin. This is highly relevant, given that women show not only a higher prevalence of ADs, but also higher associated burden and disability [60]. Notwithstanding, since men and women present general differences in body mass, sexdependent effects can also be due to different sensitivity to the administered dose. In order to clarify this question, dosedependent effects need to be explored in future studies.

The enhancing effects of insulin on fear extinction in women could also be seen $24 \mathrm{~h}$ later, with a better fear extinction recall on the SCR. Similar to the extinction phase, a sex-specific insulin effect was observed, with women in the insulin group presenting lower differential SCR at the end of re-extinction and therefore better extinction recall. Fear extinction does not erase the original fear memory, but creates a new memory that will hinder fear to reoccur. This process is, however, frail and susceptible to reappearance of the original fear memory [61]. In clinical context, it is known that relapse can occur even after successful extinction [62]. Effects on the level of extinction recall are therefore of special clinical relevance, since more important than the fear extinction is how this new learning can hold up during time. The present results show that insulin might not only enhance learning of fear extinction but also its consolidation. Considering that intranasal insulin did not affect subjective anxiety ratings nor contextual anxiety as measured by the NA trials, the present data seem to indicate an effect of intranasal insulin on fear extinction learning and not on fear expression per se.

The present study applied a randomized, double-blind, placebocontrolled differential fear-conditioning paradigm, with careful maintenance of control variables. A comparable glycemic state at the beginning of the experiment was assured by food restriction, and control throughout the experiment showed that glucose levels remained in an euglycemic level after intranasal administration, as seen in other similar studies [24, 63-65]. The observed differences between insulin and placebo group can therefore be attributed to central nervous insulin effects and not to changes in peripheral glucose levels. Based on the current information, it can only be speculated which brain structures are involved in these effects. In this regard, it is important to note that the effects of intranasal insulin were observed for two physiological measures of fear learning and extinction: FPS and SCR. Long-standing evidence indicates that the two measures have different neural correlates and therefore express different processing mechanisms. It is thought that FPS reflects a more primal form of fear learning, involving neuronal structures like the amygdala, insular cortex, and thalamus [66]. SCR is on the other hand considered to express associative fear learning and anticipatory arousal [67], accompanied by activation of the hippocampus [68]. A concerted activity of the amygdala, hippocampus, and prefrontal cortex is central during fear extinction [69]. Furthermore, the insular cortex, a structure implied in fear-conditioning possibly via interoception and awareness processes [62], has been shown to be sensitive to intranasal insulin [33]. Neuroimaging studies should target those regions to investigate on what level intranasal insulin affects fear learning and extinction.

Insulin can cross the blood-brain barrier through active transport and thus directly affect the CNS [70]. The widespread expression of IR in the brain suggests effects on a broad range of brain structures, including the above-mentioned ones. The influence of central insulin on memory functions might be mediated by different pharmacological mechanisms [71]. Similar to insulin effects in the periphery, central insulin effects include an increased release of glucose from glycogen stores and its transportation across membranes, as well as an enhanced neural uptake of glucose or glucose-analog substances [72-74]. An especially sensitive structure to the insulin-dependent energy regulation is the hippocampus [74], and glucose has been shown to increase cognitive functions $[75,76]$ and, more recently, hippocampus-dependent acquisition of fear memory [77]. It is therefore possible that enhancing effects of intranasal insulin in memory processes are actually mediated by glucose uptake. On the other hand, central insulin exerts effects through additional pathways and especially its capacity to modulate glutaminergic and GABAergic signaling, and consequently excitatory synaptic transmission have been suggested to mediate memory effects [71].

No differences between groups on the US-expectancy ratings were found; however, dissociation between subjective ratings and physiological measures has been repeatedly reported $[48,78,79]$ and is in line with the theory of multiple memory systems [80]. A limitation of the present study is that the reinstatement procedure was not successful, neither at a subjective nor at a physiological level. US-expectancy results showed, however, a spontaneous recovery of fear: the difference between the CS was already increased at the beginning of day 3, before the reinstatement procedure, compared to the end of the extinction on the previous day. It could be that the large time interval between extinction and test was enough to prompt ROF $[81,82]$, or that the context of the laboratory environment might have led to an immediate ROF $[62,83]$, which was not further exacerbated by the reinstatement procedure. It is important to note that the interval between fear acquisition and reinstatement was longer than what is commonly used in similar paradigms [59]. Although longer temporal intervals might be more ecologically valid, it is possible that the used US was not emotionally salient enough to produce reinstatement after such an interval. Moreover, given that the reinstatement procedure proceeded reextinction, it is not possible to exclude a potential influence in extinction recall. 
It is a further limitation that only women taking hormonal contraceptives were included in this study. Since sex hormones can affect not only insulin sensitivity [84] but also fearconditioning processes [85], research should be extended to women not taking oral contraceptives.

As insulin exerts a long-term regulatory signal [86], many studies focused on effects of long-term intranasal insulin administration on cognitive enhancement [20, 25, 87]. It would therefore also be important to study the effects of prolonged insulin administration on fear extinction learning. Furthermore, research with cognitive enhancers like cortisol, has shown that such hormones can have enhancing or deteriorating cognitive effects dependent on time of administration and the investigated memory process [88]. The present study cannot disentangle the effects on extinction learning and consolidation as insulin was administered before extinction learning. Future studies should focus on these different processes.

With regard to improving the effectiveness of CBT for fearrelated disorders, there is an increased need for substances improving extinction processes. We present first evidence that intranasal insulin might be a promising adjuvant to extinctionbased therapies. Further research is necessary to elucidate the effects of insulin in fear learning and extinction, especially in subclinical and clinical samples. Furthermore, sex effects need to be taken into consideration.

\section{FUNDING AND DISCLOSURE}

This work was financially supported by a Startup Funding for Research Projects from the Saarland University (Anschubfinanzierung von Forschungsprojekten im HH-Jahr 2016, 61-cl/Anschub 2016/bewFerreira). All authors declare no competing interests.

\section{ACKNOWLEDGEMENTS}

We gratefully acknowledge the assistance of the following students during data collection: Charlotte Fürstenberger, Danae Karamanidis-Boldt, Anna König, Annabell Montoya Martinez, Michael Richter, and Natalie Sers.

\section{ADDITIONAL INFORMATION}

Supplementary Information accompanies this paper at (https://doi.org/10.1038/ s41386-019-0593-3).

Publisher's note Springer Nature remains neutral with regard to jurisdictional claims in published maps and institutional affiliations.

\section{REFERENCES}

1. Wittchen $\mathrm{H}-\mathrm{U}$, Jacobi $\mathrm{F}$, Rehm J, Gustavsson A, Svensson $\mathrm{M}$, Jönsson B, et al. The size and burden of mental disorders and other disorders of the brain in Europe 2010. Eur Neuropsychopharmacol. 2011;21:655-79.

2. Patel V, Saxena S, Lund C, Thornicroft G, Baingana F, Bolton P, et al. The Lancet Commission on global mental health and sustainable development. Lancet 2018;392:1553-98.

3. Hofmann SG, Asnaani A, Vonk IJ, Sawyer AT, Fang A. The efficacy of cognitive behavioral therapy: a review of meta-analyses. Cogn Ther Res. 2012;36:427-40.

4. Arch JJ, Craske MG. First-line treatment: a critical appraisal of cognitive behavioral therapy developments and alternatives. Psychiatr Clin North Am. 2009;32:525-47.

5. Carpenter JK, Andrews LA, Witcraft SM, Powers MB, Smits JA, Hofmann SG. Cognitive behavioral therapy for anxiety and related disorders: A meta-analysis of randomized placebo-controlled trials. Depress Anxiety. 2018;35:502-14.

6. Bentz D, Michael T, de Quervain DJ, Wilhelm FH. Enhancing exposure therapy for anxiety disorders with glucocorticoids: from basic mechanisms of emotional learning to clinical applications. J Anxiety Disord. 2010;24:223-30.

7. Hermans D, Craske MG, Mineka S, Lovibond PF. Extinction in human fear conditioning. Biol Psychiatry. 2006;60:361-68.

8. Michael T, Blechert J, Vriends N, Margraf J, Wilhelm FH. Fear conditioning in panic disorder: enhanced resistance to extinction. J Abnorm Psychol. 2007;116:612-7.
9. Blechert J, Michael T, Grossman P, Lajtman M, Wilhelm FH. Autonomic and respiratory characteristics of posttraumatic stress disorder and panic disorder. Psychosom Med. 2007;69:935-43.

10. Forcadell E, Torrents-Rodas D, Vervliet B, Leiva D, Tortella-Feliu M, Fullana MA. Does fear extinction in the laboratory predict outcomes of exposure therapy? A treatment analog study. Int J Psychophysiol. 2017;121:63-71.

11. Norberg MM, Krystal JH, Tolin DF. A meta-analysis of D-cycloserine and the facilitation of fear extinction and exposure therapy. Biol Psychiatry. 2008;63:1118-26.

12. de Quervain DJ, Bentz D, Michael T, Bolt OC, Wiederhold BK, Margraf J, et al. Glucocorticoids enhance extinction-based psychotherapy. Proc Natl Acad Sci USA. 2011;108:6621-5.

13. Lass-Hennemann J, Michael T. Endogenous cortisol levels influence exposure therapy in spider phobia. Behav Res Ther. 2014;60:39-45.

14. Brueckner AH, Lass-Hennemann J, Wilhelm FH, Ferreira de Sá DS, Michael T. Cortisol administration after extinction in a fear-conditioning paradigm with traumatic film clips prevents return of fear. Transl Psychiatry. 2019;9:128.

15. Stockhorst U, de Fries D, Steingrueber HJ, Scherbaum WA. Insulin and the CNS: effects on food intake, memory, and endocrine parameters and the role of intranasal insulin administration in humans. Physiol Behav. 2004;83:47-54.

16. Unger JW, Livingston JN, Moss AM. Insulin receptors in the central nervous system: localization, signalling mechanisms and functional aspects. Prog Neurobiol. 1991;36:343-62.

17. Plum $L$, Schubert $M$, Bruning JC. The role of insulin receptor signaling in the brain Trends Endocrinol Metab. 2005;16:59-65.

18. Schulingkamp RJ, Pagano TC, Hung D, Raffa RB. Insulin receptors and insulin action in the brain: review and clinical implications. Neurosci Biobehav Rev. 2000;24:855-72.

19. Zhao WQ, Chen H, Quon MJ, Alkon DL. Insulin and the insulin receptor in experimental models of learning and memory. Eur J Pharm. 2004;490:71-81.

20. Benedict C, Hallschmid M, Hatke A, Schultes B, Fehm HL, Born J, et al. Intranasal insulin improves memory in humans. Psychoneuroendocrinology 2004;29:1326-34.

21. Fish HR, Chernow B, O'Brian JT. Endocrine and neurophysiologic responses of the pituitary to insulin-induced hypoglycemia: a review. Metabolism. 1986;35:763-80.

22. Born J, Lange T, Kern W, McGregor GP, Bickel U, Fehm HL. Sniffing neuropeptides: a transnasal approach to the human brain. Nat Neurosci. 2002;5:514-6.

23. Freiherr J, Hallschmid M, Frey WH II, Brunner YF, Chapman CD, Holscher C, et al. Intranasal insulin as a treatment for Alzheimer's disease: a review of basic research and clinical evidence. CNS Drugs 2013;27:505-14.

24. Benedict C, Kern W, Schultes B, Born J, Hallschmid M. Differential sensitivity of men and women to anorexigenic and memory-improving effects of intranasal insulin. J Clin Endocrinol Metab. 2008;93:1339-44.

25. Hallschmid M, Benedict C, Schultes B, Born J, Kern W. Obese men respond to cognitive but not to catabolic brain insulin signaling. Int J Obes (Lond). 2008;32:275-82.

26. Krug R, Benedict C, Born J, Hallschmid M. Comparable sensitivity of postmenopausal and young women to the effects of intranasal insulin on food intake and working memory. J Clin Endocrinol Metab. 2010;95:E468-72.

27. Mclntyre RS, Soczynska JK, Woldeyohannes HO, Miranda A, Vaccarino A, Macqueen $\mathrm{G}$, et al. A randomized, double-blind, controlled trial evaluating the effect of intranasal insulin on neurocognitive function in euthymic patients with bipolar disorder. Bipolar Disord. 2012;14:697-706.

28. Hallschmid M, Benedict C, Schultes B, Fehm HL, Born J, Kern W. Intranasal insulin reduces body fat in men but not in women. Diabetes 2004;53:3024-9.

29. Stockhorst U, de Fries D, Steingrueber HJ, Scherbaum WA. Unconditioned and conditioned effects of intranasally administered insulin vs placebo in healthy men: a randomised controlled trial. Diabetologia. 2011;54:1502-6.

30. Bouton ME. Context and behavioral processes in extinction. Learn Mem. 2004;11:485-94.

31. Genazzani AR, Mannella $P$, Simoncini T. Drospirenone and its antialdosterone properties. Climacteric. 2007;10:11-8.

32. Shemesh E, Rudich A, Harman-Boehm I, Cukierman-Yaffe T. Effect of intranasal insulin on cognitive function: a systematic review. J Clin Endocrinol Metab. 2012;97:366-76.

33. Schilling TM, Ferreira de Sá DS, Westerhausen R, Strelzyk F, Larra MF, Hallschmid $M$, et al. Intranasal insulin increases regional cerebral blood flow in the insular cortex in men independently of cortisol manipulation. Hum Brain Mapp. 2014;35:1944-56.

34. Langner O, Dotsch R, Bijlstra G, Wigboldus DHJ, Hawk ST, van Knippenberg A Presentation and validation of the Radboud Faces Database. Cogn Emot. 2010;24:1377-88

35. Stein MB, Stein DJ. Social anxiety disorder. Lancet. 2008;371:1115-25.

36. Tost $\mathrm{H}$, Champagne FA, Meyer-Lindenberg A. Environmental influence in the brain, human welfare and mental health. Nat Neurosci. 2015;18:1421-31. 
37. Challet E. Keeping circadian time with hormones. Diabetes Obes Metab. 2015;17:76-83.

38. Stone AA, Kessler RC, Haythornthwaite JA. Measuring daily events and experiences: decisions for the researcher. J Personal. 1991;59:575-607.

39. Ferreira de Sá DS, Plein DE, Schulz A, Oitzl MS, Blumenthal TD, Schächinger H. Acoustic startle reactivity while processing reward-related food cues during food deprivation: evidence from women in different menstrual cycle phases and men. Psychophysiology. 2014;51:159-67.

40. Blumenthal TD, Cuthbert BN, Filion DL, Hackley S, Lipp OV, van Boxtel A. Committee report: guidelines for human startle eyeblink electromyographic studies. Psychophysiology. 2005;42:1-15.

41. Boucsein W, Fowles DC, Grimnes S, Ben-Shakhar G, roth WT, Dawson ME, et al. Publication recommendations for electrodermal measurements. Psychophysiology. 2012;49:1017-34.

42. Haselgrove $M$, Aydin A, Pearce JM. A partial reinforcement extinction effect despite equal rates of reinforcement during Pavlovian conditioning. J Exp Psychol Anim Behav Process. 2004;30:240-50.

43. Blechert J, Peyk P, Liedlgruber M, Wilhelm FH. ANSLAB: Integrated multichannel peripheral biosignal processing in psychophysiological science. Behav Res Methods. 2016;48:1528-45.

44. Bentz D, Michael T, Wilhelm FH, Hartmann FR, Kunz S, von Rohr IR, et al. Influence of stress on fear memory processes in an aversive differential conditioning paradigm in humans. Psychoneuroendocrinology. 2013;38:1186-97.

45. Bos MG, Beckers $T$, Kindt $M$. The effects of noradrenergic blockade on extinction in humans. Biol Psychol. 2012;89:598-605.

46. Vriends N, Michael T, Blechert J, Meyer AH, Margraf J, Wilhelm FH. The influence of state anxiety on the acquisition and extinction of fear. J Behav Ther Exp Psychiatry. 2011;42:46-53.

47. Wegerer M, Blechert J, Kerschbaum H, Wilhelm FH. Relationship between fear conditionability and aversive memories: evidence from a novel conditionedintrusion paradigm. PLoS ONE. 2013;8:e79025.

48. Sevenster D, Beckers T, Kindt M. Fear conditioning of SCR but not the startle reflex requires conscious discrimination of threat and safety. Front Behav Neurosci. 2014;8:32.

49. Hautzinger $M$, Keller F, Kühner C. Beck Depressions-Inventar (BDI-II). Revision. Frankfurt/Main, Germany: Harcourt Test Services; 2006.

50. Laux L, Glanzmann P, Schaffner P, Spielberger CD. Das State-Trait-Angstinventar: STAI theoretische Grundlagen und Handanweisung. Weinheim, Germany: Beltz Test; 1981.

51. Norrholm SD, Jovanovic T, Vervliet B, Myers KM, Davis M, Rothbaum BO, et al. Conditioned fear extinction and reinstatement in a human fear-potentiated startle paradigm. Learn Mem. 2006;13:681-5.

52. LaBar KS, LeDoux JE, Spencer DD, Phelps EA. Impaired fear conditioning following unilateral temporal lobectomy in humans. J Neurosci. 1995;15:6846-55.

53. Lonsdorf TB, Menz MM, Andreatta M, Fullana MA, Golkar A, Haaker J, et al. Don't fear 'fear conditioning': Methodological considerations for the design and analysis of studies on human fear acquisition, extinction, and return of fear. Neurosci Biobehav Rev. 2017;77:247-85

54. Eckstein M, Becker B, Scheele D, Scholz C, Preckel K, Schlaepfer TE, et al. Oxytocin facilitates the extinction of conditioned fear in humans. Biol Psychiatry. 2015;78:194-202.

55. Fani N, King TZ, Brewster R, Srivastava A, Stevens JS, Glover EM, et al. Fearpotentiated startle during extinction is associated with white matter microstructure and functional connectivity. Cortex. 2015;64:249-59.

56. Sjouwerman R, Niehaus J, Kuhn M, Lonsdorf TB. Don't startle me-Interference of startle probe presentations and intermittent ratings with fear acquisition. Psychophysiology. 2016:53:1889-99.

57. Ameli R, Ip C, Grillon C. Contextual fear-potentiated startle conditioning in humans: replication and extension. Psychophysiology. 2001;38:383-90.

58. Missig G, Ayers LW, Schulkin J, Rosen JB. Oxytocin reduces background anxiety in a fear-potentiated startle paradigm. Neuropsychopharmacology. 2010;35:2607.

59. Haaker J, Golkar A, Hermans D, Lonsdorf TB. A review on human reinstatement studies: an overview and methodological challenges. Learn Mem. 2014;21:424-40.

60. McLean CP, Asnaani A, Litz BT, Hofmann SG. Gender differences in anxiety disorders: prevalence, course of illness, comorbidity and burden of illness. J Psychiatr Res. 2011:45:1027-35.

61. Bouton ME. Context, ambiguity, and unlearning: sources of relapse after behavioral extinction. Biol Psychiatry. 2002;52:976-86.
62. Vervliet B, Craske MG, Hermans D. Fear extinction and relapse: state of the art. Annu Rev Clin Psychol. 2013;9:215-48.

63. Benedict C, Frey WH II, Schioth HB, Schultes B, Born J, Hallschmid M. Intranasal insulin as a therapeutic option in the treatment of cognitive impairments. Exp Gerontol. 2011;46:112-5.

64. Hallschmid M, Higgs S, Thienel M, Ott V, Lehnert H. Postprandial administration of intranasal insulin intensifies satiety and reduces intake of palatable snacks in women. Diabetes. 2012;61:782-9.

65. Ferreira de Sa DS, Schulz A, Streit FE, Turner JD, Oitzl MS, Blumenthal TD, et al. Cortisol, but not intranasal insulin, affects the central processing of visual food cues. Psychoneuroendocrinology. 2014;50:311-20.

66. Davis M. Neural systems involved in fear and anxiety measured with fearpotentiated startle. Am Psychol. 2006;61:741-56.

67. Soeter $M$, Kindt M. Dissociating response systems: erasing fear from memory. Neurobiol Learn Mem. 2010;94:30-41.

68. Hamm AO, Weike Al. The neuropsychology of fear learning and fear regulation. Int J Psychophysiol. 2005;57:5-14.

69. Milad MR, Quirk GJ. Fear extinction as a model for translational neuroscience: ten years of progress. Annu Rev Psychol. 2012;63:129-51.

70. Woods SC, Seeley RJ, Baskin DG, Schwartz MW. Insulin and the blood-brain barrier. Curr Pharm Des. 2003;9:795.

71. Ghasemi R, Haeri A, Dargahi L, Mohamed Z, Ahmadiani A. Insulin in the brain: sources, localization and functions. Mol Neurobiol. 2013;47:145-71.

72. Wozniak M, Rydzewski B, Baker SP, Raizada MK. The cellular and physiological actions of insulin in the central nervous system. Neurochem Int. 1993;22:1-10.

73. Schulingkamp R, Pagano T, Hung D, Raffa R. Insulin receptors and insulin action in the brain: review and clinical implications. Neurosci Biobehav Rev. 2000;24:855-72.

74. Park C. Cognitive effects of insulin in the central nervous system. Neurosci Biobehav Rev. 2001;25:311-23.

75. Korol DL, Gold PE. Glucose, memory, and aging. Am J Clin Nutr. 1998:67:764S-71S

76. Scholey AB, Harper S, Kennedy DO. Cognitive demand and blood glucose. Physiol Behav. 2001;73:585-92.

77. Glenn DE, Minor TR, Vervliet B, Craske MG. The effect of glucose on hippocampaldependent contextual fear conditioning. Biol Psychiatry. 2014;75:847-54.

78. Blechert J, Michael T, Williams SL, Purkis HM, Wilhelm FH. When two paradigms meet: does evaluative learning extinguish in differential fear conditioning? Learn Motiv. 2008;39:58-70.

79. Acheson D, Feifel D, de Wilde S, McKinney R, Lohr J, Risbrough V. The effect of intranasal oxytocin treatment on conditioned fear extinction and recall in a healthy human sample. Psychopharmacology (Berl). 2013;229:199-208.

80. Phelps EA. Human emotion and memory: interactions of the amygdala and hippocampal complex. Curr Opin Neurobiol. 2004;14:198-202.

81. Norrholm SD, Vervliet B, Jovanovic T, Boshoven W, Myers KM, Davis M, et al. Timing of extinction relative to acquisition: a parametric analysis of fear extinction in humans. Behav Neurosci. 2008;122:1016-30.

82. Schiller D, Cain CK, Curley NG, Schwartz JS, Stern SA, Ledoux JE, et al. Evidence for recovery of fear following immediate extinction in rats and humans. Learn Mem. 2008;15:394-402.

83. Kull S, Muller BH, Blechert J, Wilhelm FH, Michael T. Reinstatement of fear in humans: autonomic and experiential responses in a differential conditioning paradigm. Acta Psychol (Amst). 2012;140:43-9.

84. Lindheim SR, Presser SC, Ditkoff EC, Vijod MA, Stanczyk FZ, Lobo RA. A possible bimodal effect of estrogen on insulin sensitivity in postmenopausal women and the attenuating effect of added progestin. Fertil Steril. 1993;60:664-7.

85. Milad MR, Goldstein JM, Orr SP, Wedig MM, Klibanski A, Pitman RK, et al. Fear conditioning and extinction: influence of sex and menstrual cycle in healthy humans. Behav Neurosci. 2006:120:1196-203.

86. Havel PJ. Peripheral signals conveying metabolic information to the brain: shortterm and long-term regulation of food intake and energy homeostasis. Exp Biol Med. 2001;226:963-77.

87. Benedict C, Hallschmid M, Schmitz K, Schultes B, Ratter F, Fehm HL, et al. Intranasal insulin improves memory in humans: superiority of insulin aspart. Neuropsychopharmacology. 2007:32:239-43.

88. Schwabe L, Joels M, Roozendaal B, Wolf OT, Oitzl MS. Stress effects on memory: an update and integration. Neurosci Biobehav Rev. 2012;36:1740-9. 